7. J. Karamata, Sur quelques inversions d'une proposition de Cauchy, Tôhoku Math. J. vol. 36 (1933) pp. 22-28.

8. H. R. Pitt, Mercerian theorems, Proc. Cambridge Philos. Soc. vol. 34 (1938) pp. 510-520.

9. W. W. Rogosinski, On Hausdorf's methods of summability, Proc. Cambridge Philos. Soc. vol. 38 (1942) pp. 166-192.

10. G. H. Hardy, Divergent series, Oxford, 1949.

11. E. R. Love, Mercer's summability theorem, accepted for publication in J. London Math. Soc.

University of MeLbourne

\title{
A NOTE ON GENERALIZED TAUBERIAN THEOREMS. ADDENDUM
}

\section{T. RAJAGOPAL}

Lemma 9 of my paper mentioned above, in Proceedings of the American Mathematical Society vol. 2 (1951) pp. 335-349, may be stated thus.

Lemma. If there exists a sequence $\left\{\lambda_{p}\right\}$ such that $1<\lambda_{p} \rightarrow 1$ as $p \rightarrow \infty$ and

$$
\begin{aligned}
\underset{u \rightarrow \infty}{\lim \text { inf }} \underset{u<u^{\prime}<\lambda_{p} u}{\text { lower bound }}\left\{A\left(u^{\prime}\right)-A(u)\right\} \\
=\left\{\begin{array}{cc}
\text { either } & o_{L}\left(\lambda_{p}-1\right), \\
\text { or } & o_{L}\left(\log \lambda_{p}\right),
\end{array} \text { as } p \rightarrow \infty,\right.
\end{aligned}
$$

then

$$
\begin{aligned}
& \liminf _{u \rightarrow \infty} A(u)=\liminf _{u \rightarrow \infty} \frac{1}{u} \int_{0}^{u} A(x) d x, \\
& \limsup _{u \rightarrow \infty} A(u)=\limsup _{u \rightarrow \infty} \frac{1}{u} \int_{0}^{u} A(x) d x .
\end{aligned}
$$

Dr. T. Vijayaraghavan has kindly pointed out to me that the proof of (3) which I have merely indicated might require some clarification as follows.

Taking one of the alternatives of (1), say the first, we can show that it implies, for any $\lambda>1$,

Received by the editors October 19, 1951. 


$$
\underset{u<u^{\prime}<\lambda u}{\text { lower bound }}\left\{A\left(u^{\prime}\right)-A(u)\right\}=o_{L}(1)(\lambda-1) \quad \text { as } u \rightarrow \infty .
$$

For, the first alternative of (1) shows that we can find $\lambda_{p}<\lambda$ such that, for all large $u$,

$$
A\left(u^{\prime}\right)-A(u)>-\frac{\epsilon}{2}\left(\lambda_{p}-1\right), \quad u<u^{\prime}<\lambda_{p} u .
$$

Plainly there is a positive integer $r \geqq 2$ such that $\lambda_{p}^{r-1}<\lambda \leqq \lambda_{p}^{r}$ and so (4) gives, for all large $u$ and $u<u^{\prime}<\lambda u$,

$$
\begin{aligned}
A\left(u^{\prime}\right)-A(u)= & \left\{A\left(u^{\prime}\right)-A\left(\lambda_{p}^{r-1} u\right)\right\}+\left\{A\left(\lambda_{p}^{r-1} u\right)-A\left(\lambda_{p}^{r-2} u\right)\right\}+\cdots \\
& +\left\{A\left(\lambda_{p} u\right)-A(u)\right\} \\
> & -\frac{\epsilon}{2} r\left(\lambda_{p}-1\right)>-\frac{\epsilon}{2} \frac{r}{r-1}\left(\lambda_{p}^{r-1}-1\right) \\
> & -\epsilon(\lambda-1) .
\end{aligned}
$$

The last inequality leads at once to $\left(1^{\prime}\right)$.

If we are given the first alternative of (1), we write it in the form $\left(1^{\prime}\right)$ and use $\left(1^{\prime}\right)$ in connection with familiar arguments such as those of Karamata referred to in my paper [cf. S. Minakshisundaram, On generalised Tauberian theorems, Math. Zeit. vol. 45 (1939) pp. 495$506, \$ 5.1]$. The second alternative of (1) can be used to prove (3) in the same way.

I take this opportunity to correct a mistake which appears in the step preceding (4.10), p. 345 , of my paper. The step in question is

$$
\lim _{u \rightarrow \infty} \inf \text { lower bound }\left[\sigma_{1}\left(u^{\prime}\right)-\sigma_{1}(u)\right]=o_{L}(1) \log \lambda, \quad u \rightarrow \infty,
$$

and it should be read without lim $\inf _{u \rightarrow \infty}$ on the left side.

Ramanujan Institute of Mathematics, Madras 